\title{
Study of stability and thermodynamic properties of water-in-diesel nanoemulsion fuels with nano-Al additive
}

\author{
Rakhi N. Mehta $\cdot$ Utkarsh More $\cdot$ Naved Malek • \\ Mousumi Chakraborty $\cdot$ Parimal A. Parikh
}

Received: 14 October 2014 / Accepted: 24 November 2014/Published online: 8 January 2015

(c) The Author(s) 2015. This article is published with open access at Springerlink.com

\begin{abstract}
The present work addresses the formation of water-in-diesel (W/D) nanoemulsion by blending different percentages of water along with nano-Al additive in various propositions to enhance the combustion characteristics. The roles of various surfactants such as Sorbitan monooleate (Span 80), Triton X-100, Tetradecyltrimethylammonium bromide, and newly synthesized and characterized dicationic surfactants were discussed based upon their ability to stabilize the nanoemulsions. Surface active properties of the surfactants were determined by measuring their interfacial tension and subsequently by measuring the critical micelle concentration of the surfactants. Triton X-100 was found to be the most efficient surfactant for the current water-indiesel nanoemulsion as it stabilized the suspensions for more than $8 \mathrm{~h}$. Particle size analysis proved emulsion size to be in the order of nanometer, and zeta potential values were found to have neutral behavior at water-diesel interface. Experimental studies confirmed that that blends W/D [1\% (vol.) water] and W/DA [1\% (vol.) water, $0.1 \%$ (wt.) nano-Al] were thermodynamically stable.
\end{abstract}

R. N. Mehta · M. Chakraborty $(\square) \cdot$ P. A. Parikh ( $\square)$ Chemical Engineering Department, Sarvajanik College of Engineering and Technology, Surat 395 001, India e-mail: mch@ched.svnit.ac.in

P. A. Parikh

e-mail: pap@ched.svnit.ac.in

R. N. Mehta · M. Chakraborty · P. A. Parikh Chemical Engineering Department, S.V. National Institute of Technology, Surat 395 007, India

U. More · N. Malek $(\square)$

Applied Chemistry Department, S.V. National Institute of Technology, Surat 395 007, India

e-mail: navedmalek@yahoo.co.in
Keywords Nanoemulsion - Zeta potential · Backscattering profiles · Critical micelle concentration . Interfacial tension

\section{Introduction}

Micro and/or nanoemulsions widely used in the combustion process of fuels in order to improve the engine efficiency are optically isotropic and thermodynamically stable mixtures of oil, water, and surfactant (Danielsson and Lindman 1981). They offer the extended advantages for use in various fields of study, including enhanced oil recovery, surfactant-enhanced aquifer remediation (SEAR), alternative fuel, detergency, pharmaceutical, and cosmetic preparations plus many other applications (Harwell et al. 1991; Lif et al. 2010; Heuschkel et al. 2008).

Water as one of the constituents of the water-diesel emulsions, in the form of micrometer/nanometer-sized droplets exerts positive effects on the combustion of fuels. Due to their lower boiling point than diesel, water droplets present in the form of small emulsions encapsulated in diesel fuel vaporizes first under superheated conditions of engine. Such vaporization causes explosion of diesel droplets and improves atomization of fuel, evaporation rate, and eventually enhances fuel-air mixing process. Such microexplosions improve combustion process and engine efficiency and also suppress soot formation (Anna and Krister 2006; Kadota and Yamasaki 2002). Microemulsions are transparent and thermodynamically stable; however, nanoemulsions are kinetically stable (Hoar and Schulman 1943; Ruckenstein and Chi 1960; Overbeek 1978) due to small droplet size and constant Brownian motion which decelerates sedimentation or creaming. This eventually improves the stability of emulsion fuel. 
Emulsions are classified as water-in-oil (W/O) or oil-inwater $(\mathrm{O} / \mathrm{W})$ depending on which phase constitutes the disperse phase (Shinoda and Saito 1968). Water-in-oil nanoemulsions have been in limelight since it was first reported by Landfester et al. (2000). Formulation methods of microemulsions or nanoemulsions also govern droplet size distributions, thereby influencing the emulsion stability. Formation of emulsions in nanometer range (50-200 nm) can be achieved by different methods such as ultrasonication (physical stabilization) and chemical emulsification (chemical stabilization) together known as high-energy emulsification methods (Kentish et al. 2008), where high-shear stirring, high-pressure homogenizers, or ultrasonicators are used. Another low-energy emulsification method is phase inversion temperature (PIT), which is a more cost-effective option as it utilizes energy stored in the system to promote the formation of small droplets (Courrier et al. 2004; Friberg 2011). Using water-diesel emulsion fuel in a diesel engine leads to prolongation of ignition delay causing high pre-mixed combustion rate, heat release rate, and peak pressure and rough engine operation (Harbach and Agosta 1991); nonetheless, emulsion fuels can consistently curtail emissions of hydrocarbon (HC), carbon monoxide $(\mathrm{CO})$, carbon dioxide $\left(\mathrm{CO}_{2}\right)$, and especially the hazardous NOx (Nitrous Oxides), and also particulate matters (PM) (Lin and Wang 2004; Chen and Tao 2005).

Recent studies have shown that blending of nanoenergetic particles such as nanoaluminum (n-Al) in diesel enhances mass transfer properties, ignition temperature, and shorten ignition delay (Tyagi and Phelan 2008). Kao et al. (2008) conducted an experiment in a single cylinder diesel engine with blends of diesel-nanoaluminum particles and varying water percentage (3-6\%). They found noteworthy reduction in brake specific fuel consumption and reduced emissions of smoke and NOx. These results justified that during combustion in compression ignition (CI) engine, nanoaluminum reacted with water liberating hydrogen which burnt as clean fuel along with diesel, thereby improving brake power and lesser emissions (Kao et al. 2008; Yang et al. 2013; Sadhik and Anand 2011).

The objectives of the current work were to formulate water-in-diesel nanoemulsion fuel with different percentages of water and aluminum nanoparticles, and to study the effect of type and concentrations of surfactants on the stability of nanoemulsions by determining critical micelle concentration (CMC) along with surface active properties and thermodynamic properties of different emulsifiers such as surface excess concentration $\left(\Gamma_{\max }\right)$, minimum surface area per molecule $\left(A_{\min }\right)$, effectiveness $(\Pi)$, standard free energy $\left(\Delta G_{\text {mic }}\right)$, and thermodynamic parameter value of adsorption $\left(\Delta G_{\text {ads }}\right)$. In order to check the size of nanoemulsions formed, particle size analyzers (Zetasizer), working on the principle of dynamic light scattering and zeta potential, are used. Backscattering profiles are studied to check the stability of nanoemulsion fuel.

\section{Experimental}

\section{Materials}

Surfactants, such as Sorbitan monooleate (Span 80), Triton X-100 Tetradecyltrimethylammonium bromide (TTAB) were purchased from Sigma-Aldrich of high-purity grade (99\%) and used as received without further purification. 1,6-Dibromohexane (98\%) was purchased from Spectrochem and with the stated label of purity. $N, N$-Dimethyl tetradecylamine and $N, N$-Dimethyl dodecylamine were purchased from Sigma-Aldrich Ltd. and used as received. Ethyl acetate (Finar $99 \%$ ), n-hexane (Finar $95 \%$ ), acetone (Merck $\geq 99 \%$ ), double distilled, deionized water was used from the chemical lab. Diesel and NanoAluminum (n-Al, 5-150 nm) were from local market (99.9\%) and Nanoshel LLC, USA), respectively. Cationic Gemini surfactants or dicationic surfactants used in the current investigation were synthesized and characterized as per the method stated in the current paper.

\section{Synthesis of cationic gemini surfactants}

The gemini surfactants used in the current study, hexamethylene-1,6-bis(dodecyldimethylammonium bromide) (126-12, 2Br- ) and hexamethylene-1,6-bis(tetradecyldimethylammonium bromide) (14-6-14, $\left.2 \mathrm{Br}^{-}\right)$, were synthesized by the reaction of 1,6-dibromohexane with $N, N$-dimethyldodecylamine and $N, N$-dimethyltetradecylamine in dry ethanol, respectively. A 1:2.1 reaction mixture (slight excess of 1,6-dibromohexane ensured complete bisquaterization) was refluxed (at $80{ }^{\circ} \mathrm{C}$ ) for $48 \mathrm{~h}$. After completion (progress of the reaction was monitored by TLC), solvent was removed under vacuum from reaction mixture and the solid thus obtained was recrystallized five times from hexane and ethyl acetate mixture to obtain the compound in pure form. Figure 1 depicts the synthesis process of cationic Gemini surfactants. The overall yield of the surfactant was approximately $80 \%$. Purity of the surfactant was checked on the basis of $\mathrm{C}, \mathrm{H}, \mathrm{N}$ analysis, which was further characterized by ${ }^{1} \mathrm{H}$ NMR spectroscopy.

12-6-12, 2Br ${ }^{-}$: The ${ }^{1} \mathrm{H}-\mathrm{NMR}$ (200 MHz, $\mathrm{CDCl}_{3}, \delta$ ppm):0.86 (t, $\left.6 \mathrm{H}, 2 \times-\mathrm{CH}_{3}\right), 1.25-1.35(\mathrm{~m}, \quad 40 \mathrm{H}$, $\left.2 \times\left(\mathbf{C H}_{2}\right)_{10}-\mathrm{CH}_{3}\right), 3.31\left(\mathrm{~s}, 12 \mathrm{H}, 2 \times-\mathrm{N}-\left(\mathbf{C H}_{3}\right)_{2-}, 3.45(\mathrm{~m}\right.$, $8 \mathrm{H}, 2 \times-\mathrm{N}-\mathbf{C H}_{2}$ from spacer and $2 \times-\mathrm{N}-\mathbf{C H}_{2}$ from alkyl chain, 3.66 (s, 8H, $2 \times-\mathrm{N}-\mathrm{CH}_{2}-\mathbf{C H}_{2}-\mathbf{C H}_{2}-$ from spacer).

14-6-14, $2 \mathrm{Br}^{-}$: The ${ }^{1} \mathrm{H}-\mathrm{NMR}\left(200 \mathrm{MHz}, \mathrm{CDCl}_{3}, \delta\right.$ ppm):0.88 (t, $\left.6 \mathrm{H}, 2 \times-\mathrm{CH}_{3}\right), \quad 1.26-1.36(\mathrm{~m}, \quad 44 \mathrm{H}$, 
Fig. 1 Preparation of cationic Gemini surfactants

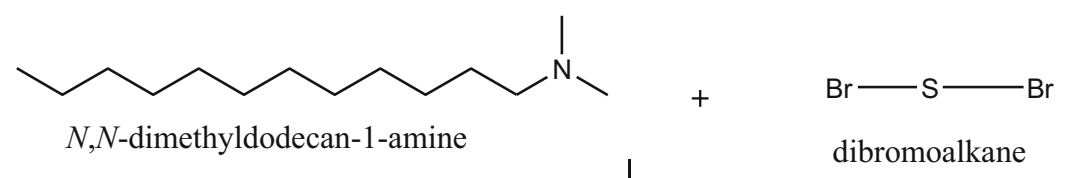

$48 \mathrm{hr}$

Ethanol

reflux

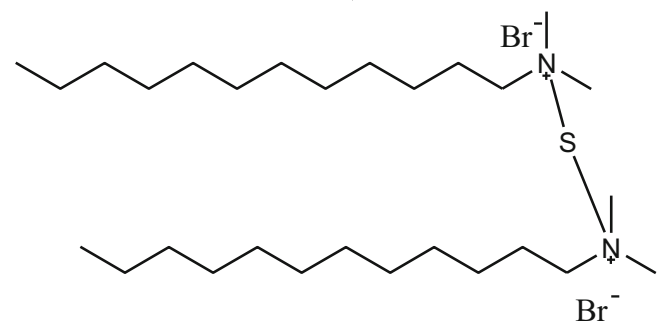

12-S-12
$\mathrm{S}=4,6$

$\left.2 \times-\left(\mathbf{C H}_{2}\right)_{11}-\mathrm{CH}_{3}\right), \quad 1.79\left(\mathrm{~s}, \quad 2 \mathrm{H}, \quad-\mathbf{C H}_{\mathbf{2}}-\left(\mathrm{CH}_{2}\right)_{11}-\mathrm{CH}_{3}\right)$, $2.41\left(\mathrm{~s}, 2 \mathrm{H},-\mathrm{N}-\mathbf{C H}_{2}-\mathrm{CH}_{2}-\left(\mathrm{CH}_{2}\right)_{11}-\mathrm{CH}_{3}\right), 3.39(\mathrm{~s}, 12 \mathrm{H}$, $2 \times-\mathrm{N}-\left(\mathbf{C H}_{3}\right)_{2-}, 3.51\left(\mathrm{~m}, 8 \mathrm{H}, 2 \times-\mathrm{N}-\mathbf{C H}_{2}\right.$ from spacer and $2 \times-\mathrm{N}-\mathbf{C H}_{2}$ from alkyl chain, $3.86(\mathrm{~s}, 8 \mathrm{H}, 2 \times-\mathrm{N}-$ $\mathrm{CH}_{2}-\mathbf{C H}_{2}-\mathbf{C H}_{2}-$ from spacer).

Selection of surfactant

Emulsion droplets are normally stabilized by surfactants or amphiphilic polymers. The adsorbed surfactant causes lowering in interfacial tension between water molecules and diesel which further promotes easier emulsification and stabilizes the droplet against coalescence by steric or electrostatic repulsion. Amount of emulsifier added to stabilize the blends also plays an important role in keeping the suspensions in single phase. But higher than required concentration (Critical Micelle concentration), may lead to crowding effect of micelles which eventually increase the viscosity. Table 1 shows the properties of surfactants added in the diesel-water emulsions in order to effectively reduce their interfacial tension and improve stability.

Table 1 Properties of surfactants

\begin{tabular}{lllrl}
\hline Surfactant & $\begin{array}{l}\text { Chemical } \\
\text { formulae }\end{array}$ & $\begin{array}{l}\text { Mol. wt. } \\
\left(\mathrm{gm} \mathrm{mol}^{-1}\right)\end{array}$ & HLB & Type \\
\hline Span 80 & $\mathrm{C}_{24} \mathrm{H}_{44} \mathrm{O}_{6}$ & 428.6 & 4.3 & Non-ionic \\
Triton X-100 & $\mathrm{C}_{14} \mathrm{H}_{22} \mathrm{O}\left(\mathrm{C}_{2} \mathrm{H}_{4} \mathrm{O}\right) n$ & 625 & 13.4 & Non-ionic \\
TTAB & $\mathrm{C}_{17} \mathrm{H}_{38} \mathrm{BrN}$ & 336.39 & - & Cationic \\
\hline
\end{tabular}

Formulation of nanoemulsion fuels

In order to keep the water droplets and nanoparticles in uniform suspension, both physical and chemical stabilization were provided. Nanoemulsions were prepared at 6,500 rpm using Ultraturax ${ }^{\circledR}$ IKA WERKE, GmBH \& Co. KG and then subjected to ultrasonic vibration (Sonics Vibra cell-USA, 750 watt, $20 \mathrm{kHz}$ frequency). The duration of physical mixing was gradually increased in the intervals of 5 upto 30 min along with a constant check for dispersion characteristics of the suspension. Nanoemulsion fuels, water-indiesel (W/D), and water-in-diesel-n-Al (W/DA) were prepared by addition of water $(0.5,1,2.5$, and $5 \%)$ by vol. and $\mathrm{n}$-Al $(0.1,0.5$ and $1.0 \%)$ by wt. in a mixture of diesel, surfactants with a constant check for emulsion droplet size.

\section{Measurement of interfacial tensions and CMC}

By varying molar concentrations of the surfactants used in the current study, interfacial tension was measured at $25^{\circ} \mathrm{C}$ using Kruss-T9 Tensiometer (Germany) within waterdiesel emulsion system. The instrument was daily regulated by bi-distilled water (conductivity $1.1 \times 10^{-6} \mathrm{ohm}^{-1}$ $\mathrm{cm}^{-1}$ at $25^{\circ} \mathrm{C}$ ).

Critical micelle concentrations were also determined with the help of interfacial tension-concentration isotherm curves (IFVC).

\section{Surface excess concentration $\left(\Gamma_{\max }\right)$}

$\Gamma_{\max }$ is a measure of the effective adsorption of surfactant at the liquid/air or liquid/liquid interface as it is the 
maximum value to which adsorption can be obtained (Rosen 1978). It can be calculated from Gibbs equation:

$\Gamma_{\max }=-(1 / \mathrm{RT})(\delta \gamma / \delta \ln C)$

where $\Gamma_{\max }$ is surface excess concentration $\left(\mathrm{mol} \mathrm{cm}{ }^{-2}\right)$, $T$ is absolute temperature $\left(273{ }^{\circ} \mathrm{C}\right), R$ is the universal gas constant $\left(R=8.314 \mathrm{~J} \mathrm{~mol}^{-1} \mathrm{deg}^{-1}\right)$, and $\delta \gamma / \delta \ln C$ is the surface activity.

\section{Minimum surface area per molecule $\left(A_{\min }\right)$}

This property determines minimum average area occupied by each adsorbed molecule at the water-diesel interface. It is determined by equation (Al-Sabah 2000),

$A_{\min }=10^{16} /\left(N_{\mathrm{A}} \cdot \Gamma_{\max }\right)$

where $\Gamma_{\max }$ is the surface excess in $\mathrm{mol} \mathrm{m} \mathrm{m}^{-2}$ and $N$ is Avogadro's number $\left(6.023 \times 10^{23}\right.$ molecules $\left.\mathrm{mol}^{-1}\right)$.

\section{Effectiveness $\pi_{C M C}$}

The effectiveness of adsorption or surface pressure $\pi_{\mathrm{CMC}}$ of the surfactants was also calculated from equation (Rosen 1978):

$\pi_{\mathrm{CMC}}=\gamma_{0}-\gamma_{\mathrm{CMC}}$

where $\gamma_{0}$ is the surface tension measured for pure water at $25{ }^{\circ} \mathrm{C}$ and $\gamma_{\mathrm{CMC}}$ is the surface tension at CMC.

\section{Thermodynamics of micellization}

Surfactant's critical micelle concentration (CMC) plays a factor in Gibb's free energy of micellization. The exact concentration of the surfactants that yield the aggregates being thermodynamically soluble is the CMC. Gibbs free energy of micellization can be approximated by Eq. 4 (AlSabagh et al. 2011):

$\Delta G_{\text {micelle }}=\mathrm{RT} \times \ln (\mathrm{CMC})$

where $\Delta G_{\text {micelle }}$ is the molar Gibbs energy of micellization, $R$ is the universal gas constant, $T$ is the absolute temperature, and CMC is the critical micelle concentration.

The thermodynamic parameter of adsorption is calculated using the following equation: (Rosen 1978)

$\Delta G_{\text {ads }}=\Delta G_{\text {micelle }}-[0.6022] \times\left[\pi_{\mathrm{cmc}} \times A_{\text {min }}\right]$

Emulsion drop size measurement and zeta potential

The dynamic light scattering (DLS) experiments were performed using Zetasizer Nano-ZS 90 (Malvern Instruments, UK) equipped with $\mathrm{He}-\mathrm{Ne}$ laser operating at a wavelength of $633 \mathrm{~nm}$ at $90^{\circ}$ scattering angle. Each measurement for a particular micellar system was repeated at least three times. The hydrodynamic diameter $\left(D_{\mathrm{h}}\right)$ was obtained by following the method of cumulants and using Stokes-Einstein equation (Mata 2006). The same equipment was used to determine zeta potential of nanoemulsion fuels.

Stability check

To ascertain the stability of suspended nanoparticles in emulsion blends which followed the Ostwald ripening phenomenon, transmission and backscattering profiles were checked by scanning the sample using light rays of $880 \mathrm{~nm}$ wavelengths in Turbiscan classic MA 2000 (Formulaction, France).

\section{Results and discussion}

Critical micelle concentration (CMC)

CMC of Span (80), Triton X-100, TTAB, Gemini surfactants (12-6-12, 2Br ${ }^{-}$and 14-6-14, 2Br $\left.{ }^{-}\right)$were determined using interfacial tension-concentration isotherm curves (IFVC) as shown in Fig. 2. As shown in Fig. 2a-e, surface tension decreased continuously and then became constant along a wide concentration range. The point of break, when the constancy of surface tension begins, was taken as the $\mathrm{CMC}$ of the system.

As shown in Fig. 2 and depicted in Table 2, the CMC and surface tension of the cationic Gemini surfactants 12-612 and 14-6-14 were much lower than that of the monocationic surfactants (TTAB) and non-ionic surfactants (Span 80 and TX-100). $A_{\text {min }}$ determined for all the surfactants used in the current study clearly showed (Table 2) that non-ionic surfactants were more applicable for the current water-diesel emulsion system as it provided more effective surface area (Span 80, $9.27 \mathrm{~nm}^{2} /$ molecule and TX-100 $9.9 \mathrm{~nm}^{2} /$ molecule). Reason for such complex phenomenon is the higher availability of surfactant molecules at the interface, thus non-ionic surfactants (neutral zeta potential) were more effective than cationic surfactants (conventional as well as dicationic ones). Studies on emulsion stability illustrated that the phenomenon that affects stable emulsion formation were globule rupture and osmotic swell which can be managed using appropriate non-ionic surfactants such as Span 80 and TX-100 (Barad et al. 2010). As per the reported literature, mixture of two non-ionic surfactants, Span 80 (hydrophobic) and Tween 80 (hydrophilic), has also been used as emulsifiers to produce stable water-indiesel emulsion fuels (Basha and Anand 2011).

Although the CMC value of the Gemini surfactants was less than that of the single chain surfactants, it was 
Fig. 2 Interfacial tensionconcentration isotherm curves of surfactants a Span 80 ,

b Triton X-100, c TTAB, d 126-12, and e 14-6-14

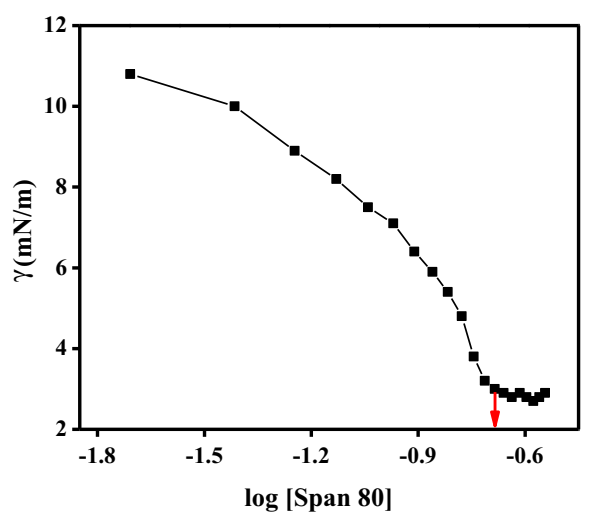

(a)

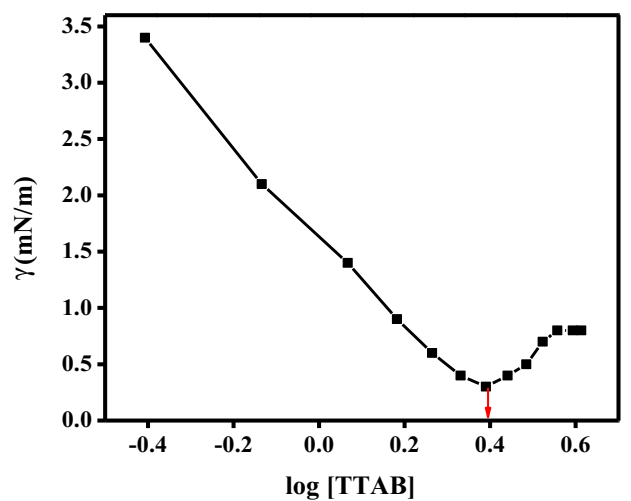

(c)

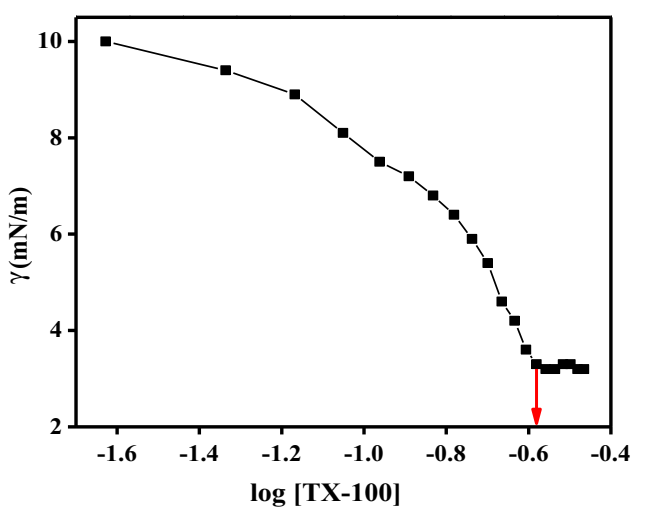

(b)

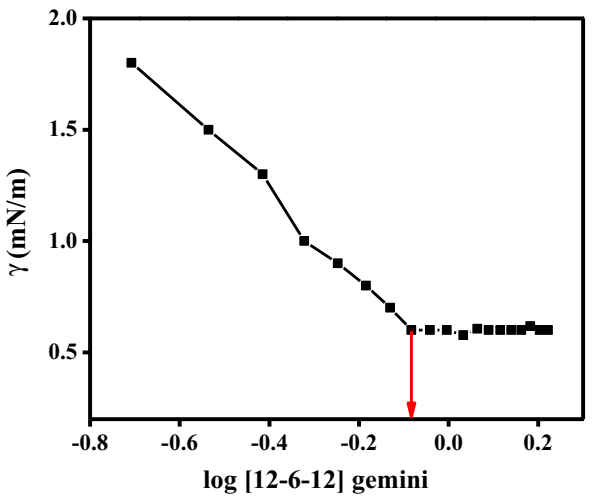

(d)

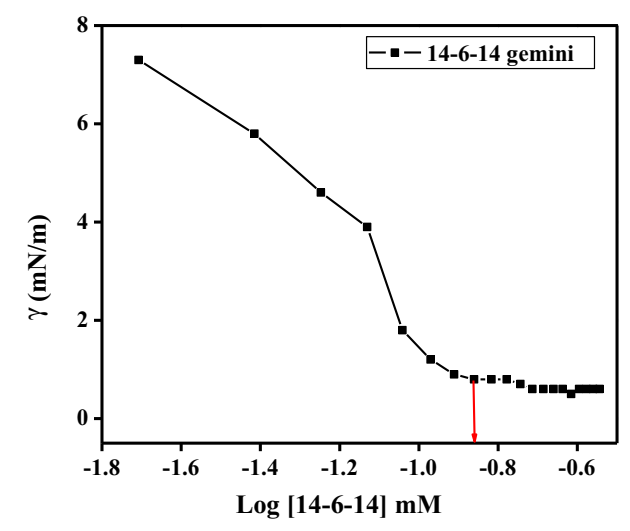

(e)

Table 2 Interfacial tension and thermodynamic properties for emulsifiers at $25^{\circ} \mathrm{C}$

\begin{tabular}{llllllll}
\hline Emulsifier & $\begin{array}{l}\mathrm{CMC} \\
\left.(\mathrm{mol} \mathrm{dm})^{-3}\right)\end{array}$ & $\begin{array}{l}\gamma_{\mathrm{IFT}} \\
\left.(\mathrm{mN} \mathrm{m})^{-1}\right)\end{array}$ & $\begin{array}{l}\Gamma_{\max } \\
\left(\times 10^{6} \mathrm{~mol} \mathrm{~m}^{-2}\right)\end{array}$ & $\begin{array}{l}A_{\min } \\
\left(\mathrm{nm}^{2} \mathrm{molecule}^{-1}\right)\end{array}$ & $\begin{array}{l}\Pi \\
\left(\mathrm{mN} \mathrm{m}^{-1}\right)\end{array}$ & $\begin{array}{l}\Delta \mathrm{G}_{\mathrm{mic}} \\
\left(\mathrm{KJ} \mathrm{mol}^{-1}\right)\end{array}$ & $\begin{array}{l}\Delta \mathrm{G}_{\mathrm{ads}} \\
\left(\mathrm{KJ} \mathrm{mol}^{-1}\right)\end{array}$ \\
\hline Span 80 & $0.194 \times 10^{-3}$ & 3.2 & 5.58 & 9.27 & 22.0 & -4.06 & -4.07 \\
TX-100 & $0.263 \times 10^{-3}$ & 3.3 & 5.97 & 9.9 & 29.9 & -3.31 & -3.31 \\
TTAB & $2.456 \times 10^{-3}$ & 0.3 & 4.53 & 7.52 & 24.6 & -2.22 & -2.22 \\
$12-6-12$ & $0.825 \times 10^{-3}$ & 0.6 & 2.13 & 3.54 & 24.4 & -0.47 & -0.48 \\
$14-6-14$ & $0.138 \times 10^{-3}$ & 0.8 & 6.39 & 0.106 & -4.90 & -4.90 \\
\hline
\end{tabular}


Fig. 3 Interface a with nonionic surfactant Triton X-100 and $\mathbf{b}$ bilayer formation with cationic surfactant
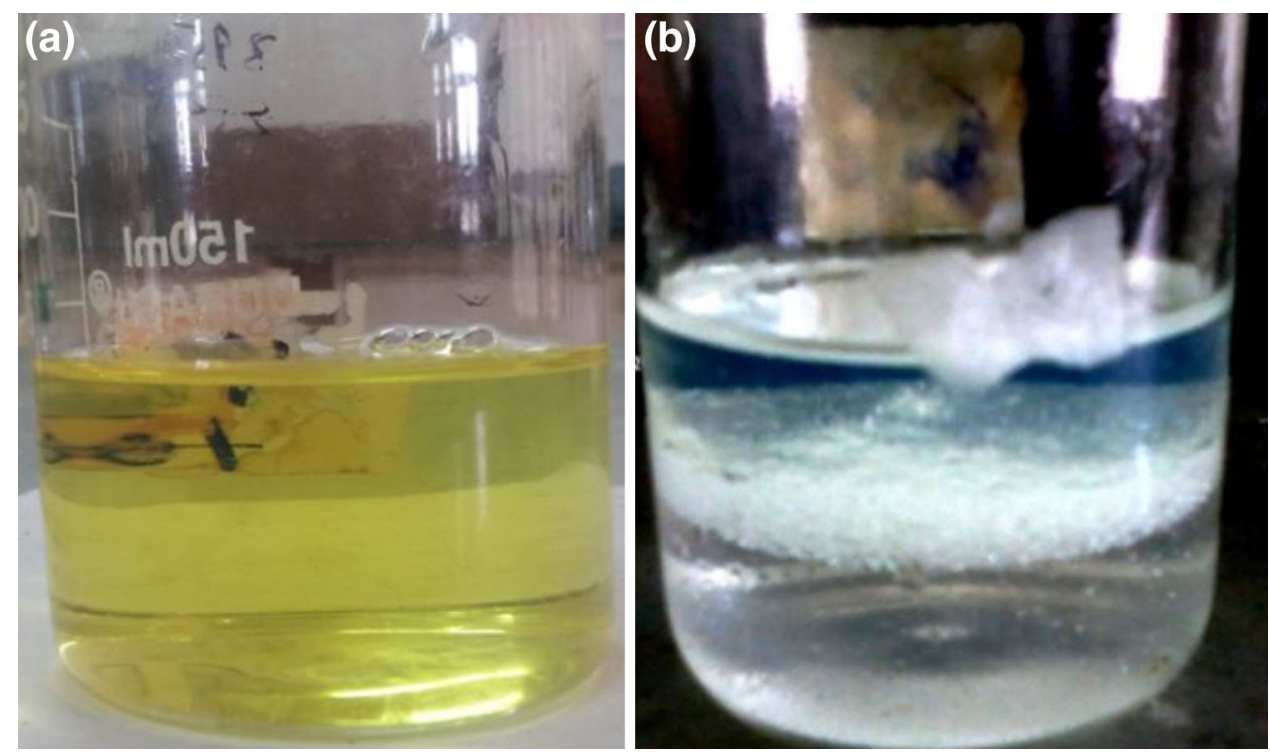

observed that beyond the CMC of these surfactants, i.e., at (0.654 and $0.12 \mathrm{mM}$ ), it formed a bilayer (Fig. 3) at the interface which implied poor emulsion properties of W/D. This may be due to the increased hydrophobicity of the medium due to the longer side chain as well as the longer spacer unit of the Gemini surfactants. TTAB and non-ionic surfactants, such as Span 80 and Triton X-100, did not form bilayer and were used to achieve the better emulsifier capacity. However, emulsion with TTAB resulted in a milky white solution after couple of hours, so it was not used for the further experiment. Both Span 80 and Triton $\mathrm{X}$-100 formed stable nanoemulsion; however, due to higher effectiveness adsorption $\left(\pi_{\mathrm{CMC}}\right)$ factor of TX-100 (Table 2), it was chosen for stabilizing nanoemulsion fuels.

Interfacial tension and surface active properties

Nanoemulsion formation demands breaking up of larger water droplets into smaller one which requires overcoming of strong Laplace pressure, $P=2 \gamma / R$, where $R$ is the average radius of curvature of spherical emulsion drop (AlSabagh et al. 2011). Emulsification includes droplet breakup, adsorption of surfactants, droplet collision which after a time span results into coalescence of droplets (Porrasa et al. 2004). Different thermodynamic properties related to interfacial tension and $\mathrm{CMC}$ values have been tabulated in Table 2.

\section{Emulsion size analysis}

In order to ascertain whether diesel-water emulsions prepared were nanoemulsions or microemulsions, all samples were tested in Zetasizer. Figure 4 depicts emulsion size analysis of emulsion fuels with $0.5,1,2.5$, and $5 \%$ waterin-diesel.

It could be incurred from the curves that with the increase in percentage of water, the size of droplets increased. It was also observed that with passage of time, emulsions swelled in size which might be attributed to coalescence and Ostwald ripening phenomenon. If coalescence was the driving force for emulsion instability, changes in droplet size with time are described by the following equation ( $\mathrm{Wu} 2001)$.

$1 / r^{2}=1 / r_{o}^{2}-8 \pi / 3 \omega t$

where $r$ is the average droplet radius at time $t, r_{\mathrm{o}}$ is the initial droplet radius, and $\omega$ is the frequency of rupture per droplet surface area. Emulsions with $0.5 \%$ water content showed minimum size as compared to those with $1,2.5$, and $5 \%$ (Fig. 4). Nonetheless, $1 \%$ water formed emulsions with droplets size in the range of 50-170 nm which justified the definition of nanoemulsions as class of emulsions with droplet size ranging from 50 to $200 \mathrm{~nm}$ (Izquierdo et al. 2005); hence, it was selected for further experiment.

Particle size analysis and zeta potential

Different concentrations $(0.1,0.5$, and $1 \%)$ of n-Al particles were suspended in diesel using surfactant (Triton $\mathrm{X}-100)$, and statistical data of particle size analysis were determined. Figure 5 represents the percentage distribution of particles as per size. It could be incurred from the plot that with the increase in concentration of $\mathrm{n}-\mathrm{Al}$ in diesel, agglomerations of particles accelerate, thereby increasing size of particles and eventually resulting in settling of 


\section{Emulsion Size Analysis}

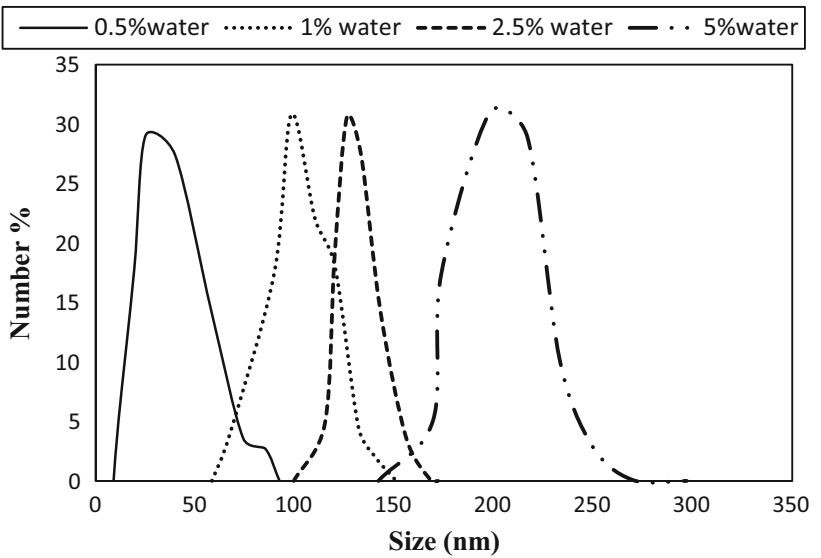

Fig. 4 Emulsion size analysis of diesel-water emulsion fuels

particles. With increase in concentration, the collision frequency of the stabilized nanoparticles increased and protection obtained by adsorption of surfactant molecules on the particles surface was weakened due to lower surfactant concentration compared to $\mathrm{n}-\mathrm{Al}$ concentration. Thus, the tiny particles agglomerated to form larger nanoparticles and settled down. However, the blend doped with $0.1 \% \mathrm{n}-\mathrm{Al}$ showed size range within $5 \mathrm{~nm}$ indicating stable blend.

Zeta potential, which is a measure of electrostatic potential at the electrical double layer surrounding a nanoparticle in solution, is generally determined to ascertain the electrical stability of nanoparticles in liquid suspensions. Nanoparticles with a zeta potential between -10 and $+10 \mathrm{mV}$ are considered approximately neutral (Clogston 2011). It could be estimated from Fig. 6 that $0.1 \%$ $\mathrm{n}$-Al doped blend showed zeta potential peak at $2.55 \mathrm{mV}$ with a narrow potential distribution. However, 0.5 and $1.0 \% \mathrm{n}$-Al doped blends showed peak at the same position with a wide range of electrostatic potential (Fig. 6). Such a widely varying zeta potential with non-uniform distribution of charges indicated the poor stability of nanoemulsions with respect to the long-term storage. These results depicted that no significant electrical double layer formed in case of $0.1 \% \mathrm{n}$-Al-diesel emulsion fuel. On the basis of particle size analysis and zeta potential study, two nanoemulsion fuels were selected, i.e., water-(1\%)-in diesel (W/D) and water (1\%) and $\mathrm{n}-\mathrm{Al}(0.1 \%)$ in diesel (W/DA) for further study.

\section{Backscattering profiles}

Another alternative mechanism that explains the instability of nanoemulsions is Ostwald ripening which arises due to the difference in solubilities between droplets with different sizes. A stable nanoemulsion should have a small mean droplet size and a large Ostwald ripening coefficient. So in order to check the duration for which selected blends could remain stable without creaming or settling and to check the
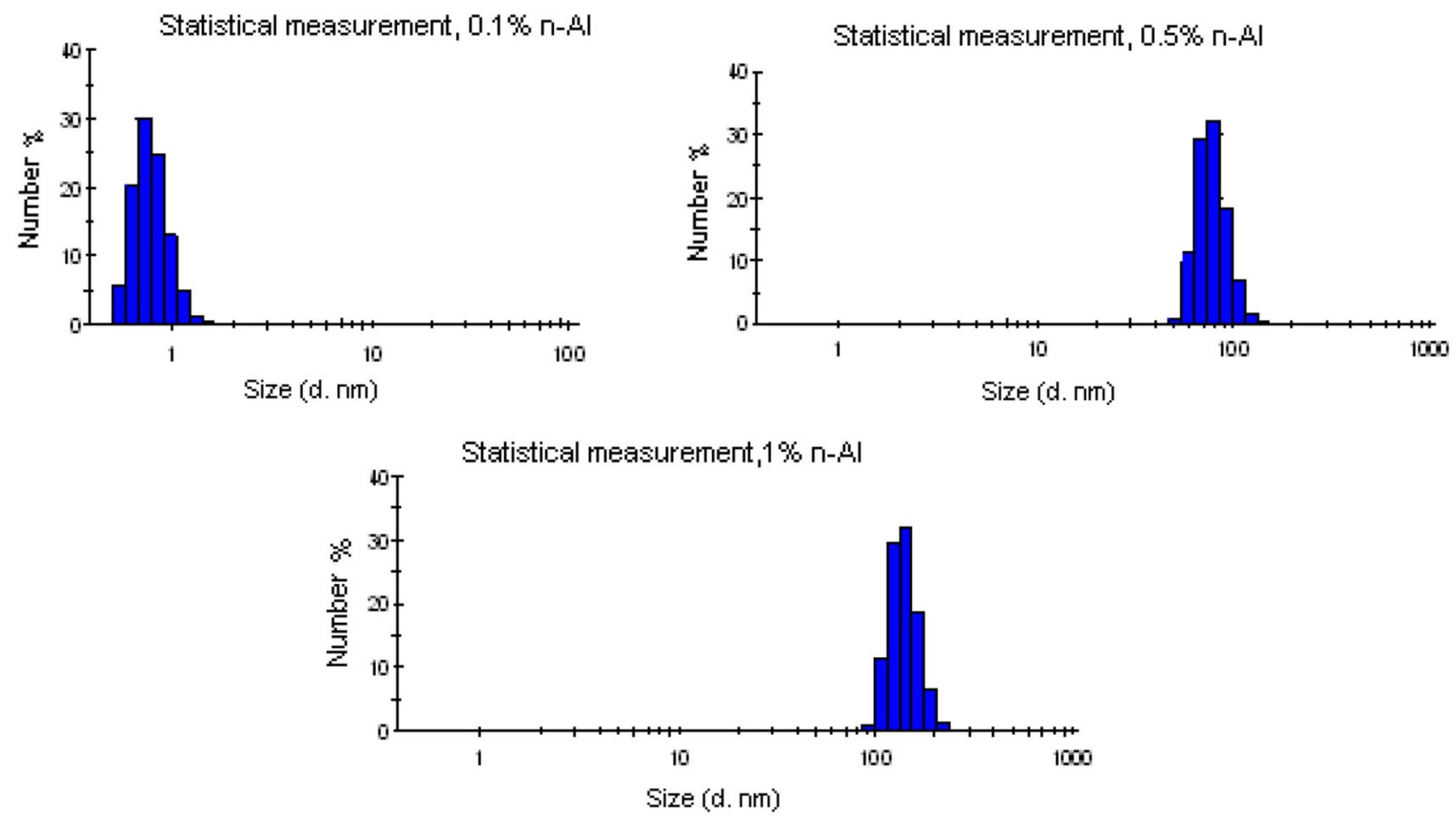

Fig. 5 Particle size analysis with different n-Al concentrations in diesel-water (1\% vol.) emulsions 
(a)

Zeta Potential Distribution

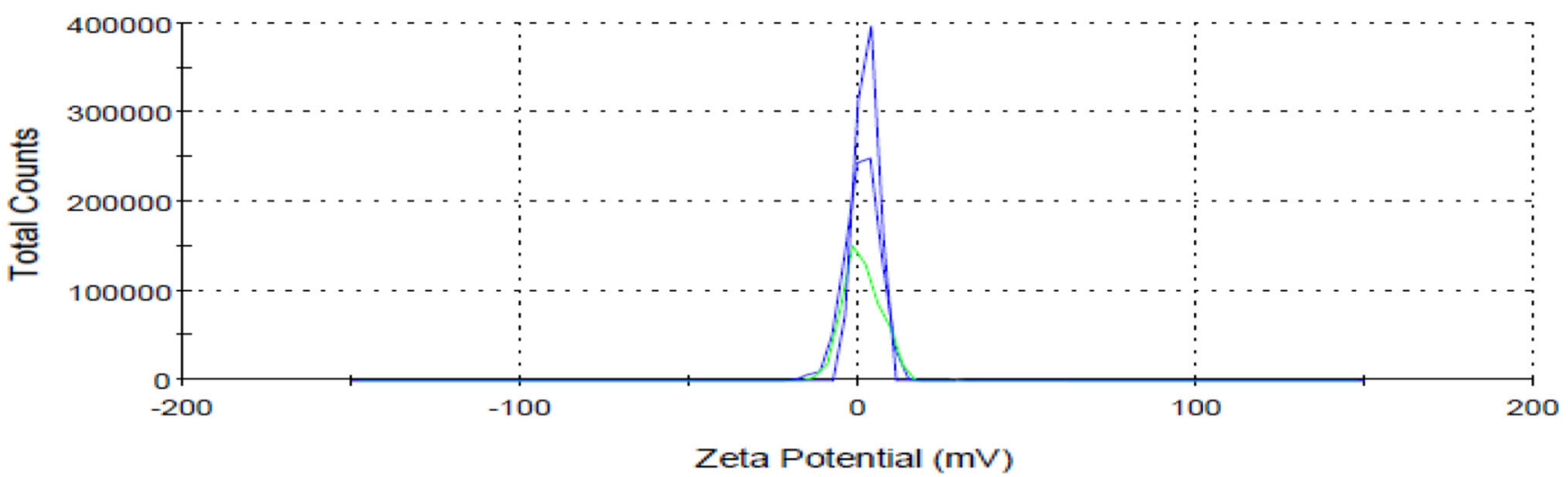

Record 1: $0.1 \% n-\mathrm{Al}_{1}$

Record 3: $0.1 \%$ ח-A.

(b)

Zeta Potential Distribution

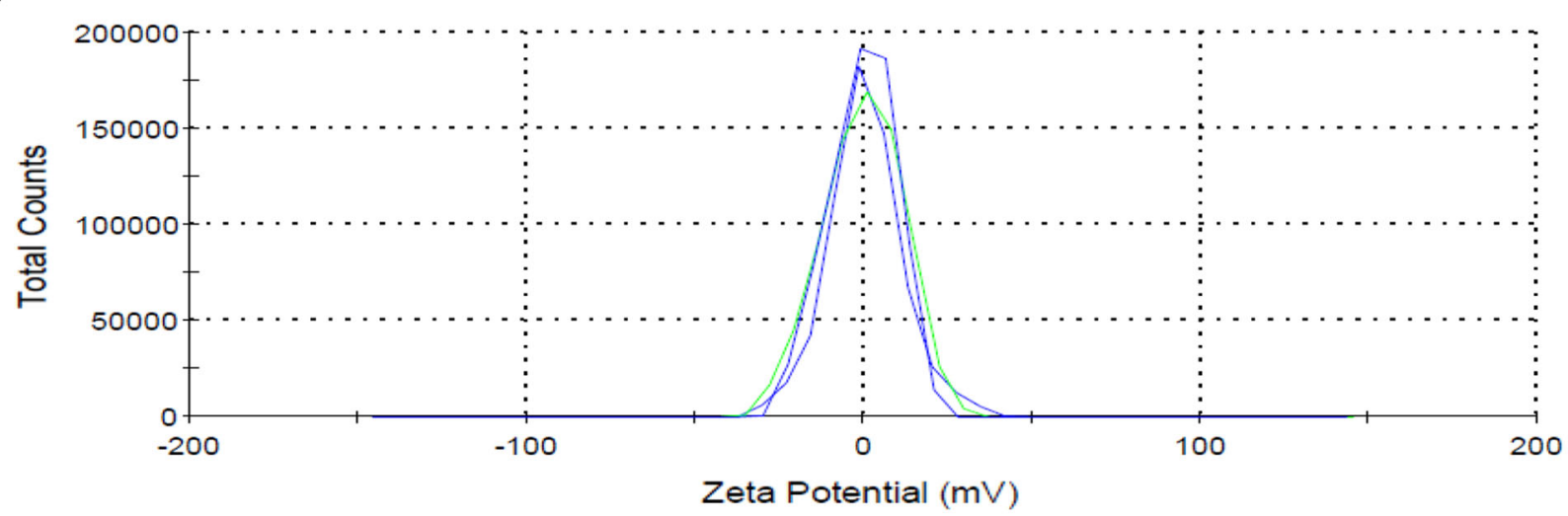

— Record 1: 0.5\% n-Al $\quad$ Record 2: 0.5\% n-Al $\quad$ Record 3: $0.5 \% \mathrm{n}$-Al

(c)

Zeta Potential Distribution

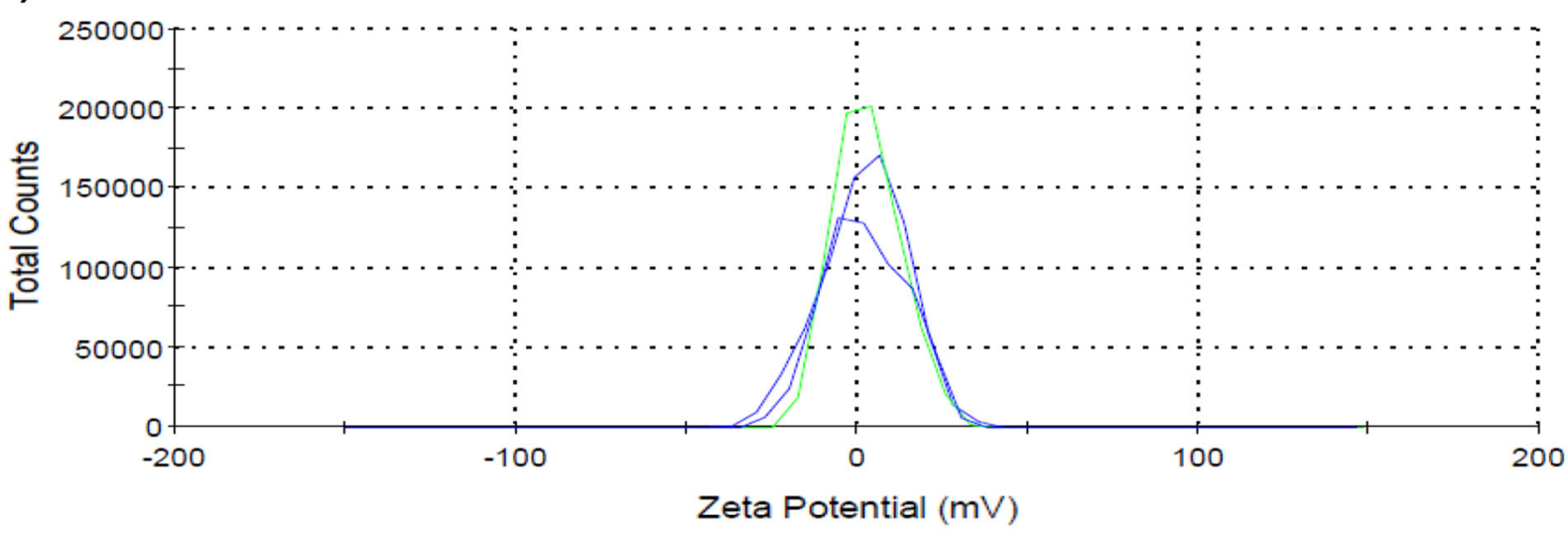

Record 1:1\% n-Al $\quad$ Record 2:1\% n-Al $\quad$ Record 3:1\% n-Al

Fig. 6 Effect of n-Al concentration a $0.1 \%$, b $0.5 \%$, and c $1 \%$ on Zeta Potential 
(a) Diesel+water(1\%) DW, $0 \mathrm{hr}$

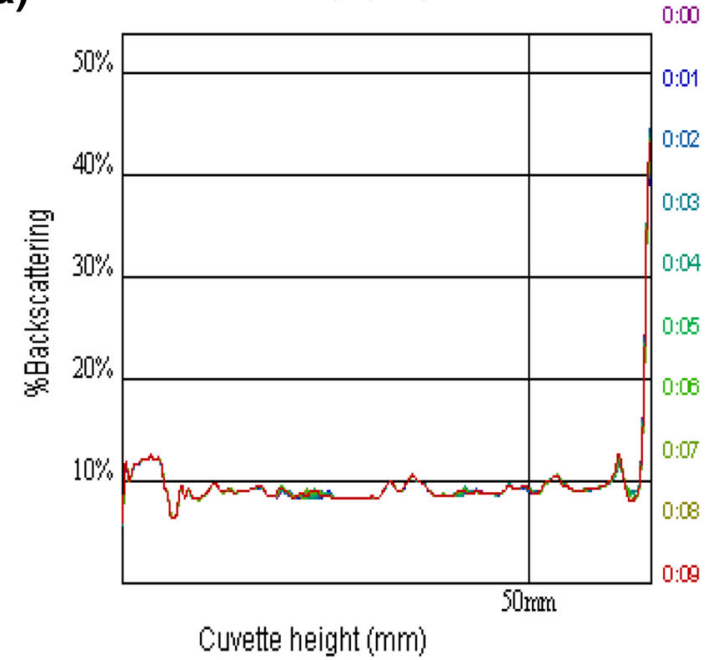

(b)

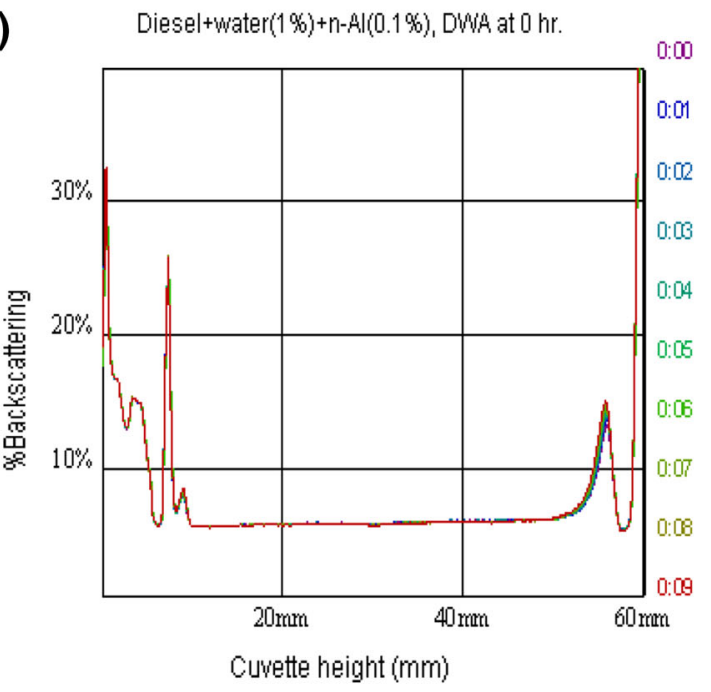

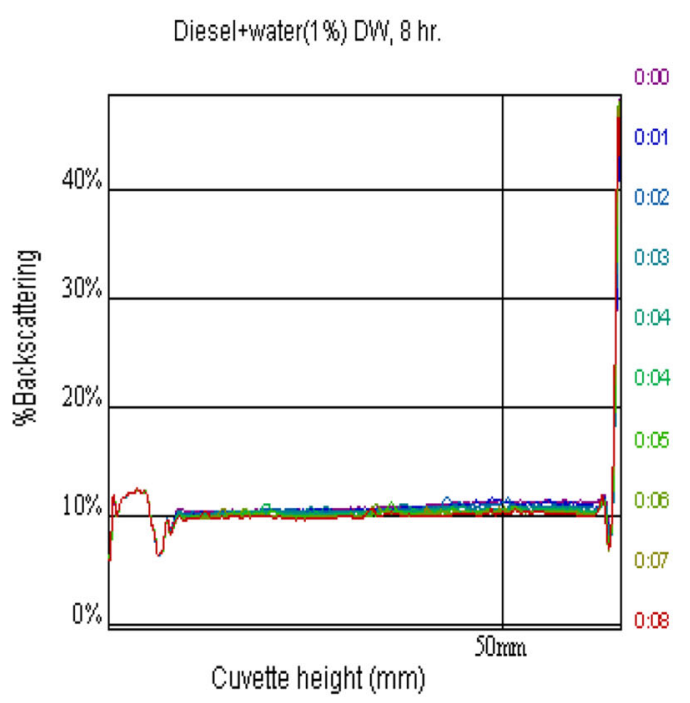

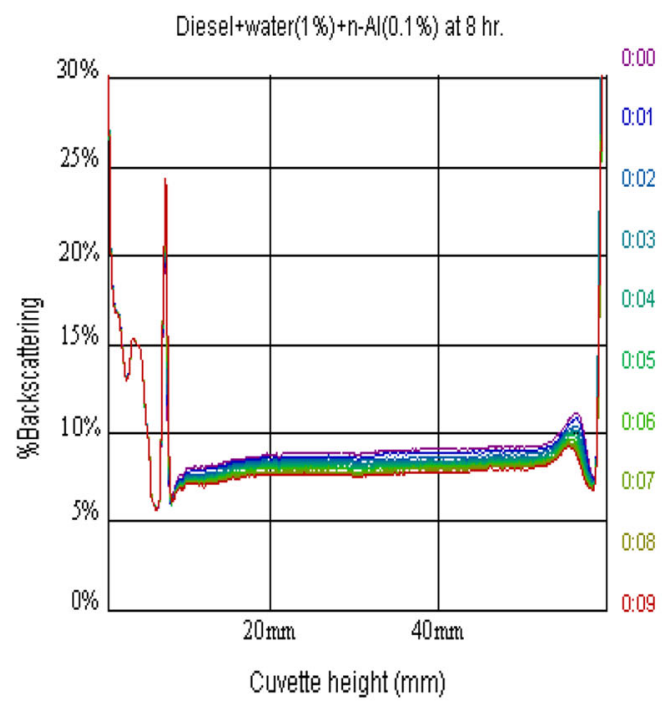

Fig. 7 Backscattering profiles of a W/D and b W/DA

effect of Ostwald ripening on extent of stability in terms of time, selected nanoemulsion fuels (W/D, W/DA) were studied for backscattering using Turbiscan.

As depicted in Fig. 7, backscattering curves coincide for nanoemulsion fuel W/D just after preparation; however, with passage of time, \% backscattering (BS) increased along with the formation of larger size of emulsions. This effect might be attributed to Ostwald ripening phenomena whereby smaller water droplets diffuse toward larger ones. W/D remained stable for more than $12 \mathrm{~h}$ after which they settled completely. W/DA showed stability for $8 \mathrm{~h}$ after which particles coagulated and resulted into complete separation within $10 \mathrm{~h}$.

Based on a thermodynamic parameter and stability study, W/D and W/DA nanoemulsion fuels could be considered for further studies such as engine performance and emission studies.

\section{Conclusions}

The current study exhibits the suitability of emulsifiers to stabilize water-diesel (W/D) and water-diesel-n-Al (W/ DA) nanoemulsion fuels. Cationic Gemini surfactants (126-12) and (14-6-14) were synthesized, characterized, and checked for their roles in stabilizing nanoemulsion fuels. Single-chain conventional monocationic surfactantTTAB - and non-ionic surfactants-Span 80 and Triton $\mathrm{X}-100$ - were also employed in order to check the better emulsifying capacity. Interfacial tension-concentration isotherm curves (IFVC) were used to determine Critical micelle concentrations (CMC) of different emulsifiers. Most favorable surfactants were found by calculating thermodynamic properties such as surface excess concentration $\left(\Gamma_{\max }\right)$, minimum surface area per molecule $\left(A_{\min }\right)$, effectiveness ( $\Pi)$, standard free energy $\left(\Delta G_{\text {mic }}\right)$, and 
thermodynamic parameter value of adsorption $\left(\Delta \mathrm{G}_{\mathrm{ads}}\right)$. Particle size analysis and zeta potential study approved better stability of W/D and W/DA. Hence, these selected nanoemulsion fuels could be tested for fuel properties and engine performance in order to ascertain their applications as a future sustainable fuel alternative.

Acknowledgments N.I.M acknowledges the financial assistance by DST, Government of India (Project No. SR/FT/CS-014/2010) and CSIR, Government of India (Project No. EMR-II/2545/2011).

Open Access This article is distributed under the terms of the Creative Commons Attribution License which permits any use, distribution, and reproduction in any medium, provided the original author(s) and the source are credited.

\section{References}

Al-Sabagh AM, Mostafa M, Emara MR, Aly WR (2011) Formation of water-in-diesel oil nano-emulsions using high energy method and studying some of their surface active properties. Egypt J Pet 20:17-23

Al-Sabah AM (2000) Surface activity and thermodynamic properties of water-soluble polyester surfactants based on 1,3-dicarboxymethoxybenzene used for enhanced oil recovery. Polym Adv Technol 11:48

Anna L, Krister H (2006) Water-in-diesel emulsions and related systems. Adv Colloid Interface Sci 123-126:231-239

Barad M, Chakraborty M, Bart HJ (2010) Stability and performance study of w/o/w emulsion: extraction of aromatic amines. Ind Eng Chem Res 49:5808-5815

Basha JS, Anand RB (2011) An experimental study in a CI engine using nanoadditive blended water-diesel emulsion fuel. Int $\mathrm{J}$ Green Energy 8:332-348

Chen G, Tao D (2005) An experimental study of stability of oil-water emulsion. Fuel Process Technol 86:499-508

Clogston JD, Patri AK (2011) Zeta potential measurement. Methods Mol Biol 697:63-70

Courrier HM, Vandamme TF, Krafft MP (2004) Reverse water-influorocarbon emulsions and microemulsions obtained with a fluorinated surfactant. Colloid Surf A 244(1-3):141-148

Danielsson I, Lindman B (1981) The definition of microemulsion. Colloids Surf 3:391-392

Friberg SE, Corkery RW, Blute IA (2011) Phase inversion temperature (PIT) emulsification process. J Chem Eng Data 56(12):4282-4290

Harbach JA, Agosta V (1991) Effects of emulsified fuel on combustion in a four-stroke diesel engine. J Ship Res $35: 356-363$
Harwell JH, Sabatini DA, Knox RC (1991) Surfactants for ground water remediation. Colloids Surf A 151:255-268

Heuschkel S, Goebe A, Neubert R (2008) Microemulsions-modern colloidal carrier for dermal and transdermal drug delivery. J Pharm Sci 97:603-631

Hoar TP, Schulman JH (1943) Transparent water-in-oil dispersions: the oleopathic hydro-micelle. Nature 152:102

Izquierdo P, Feng J, Esquena J, Tharward FT, Joseph CD, Garcia MJ, Azemar N, Solans C (2005) The influence of surfactant mixing ratio on nano-emulsion formation by the pit method. J Colloid Interface Sci 285:388-394

Kadota T, Yamasaki H (2002) Recent advances in the combustion of water fuel emulsion. Prog Energy Combust Sci 28:385-404

Kao MJ, Chen-Ching T, Bai-Fu L, Tsing-Tshih T (2008) Aqueous aluminum nanofluid combustion in diesel fuel. J Test Eval 36(2008) (Paper ID JTE100579)

Kentish S, Wooster TJ, Ashokkumar M, Balachandran S, Mawson R, Simons L (2008) The use of ultrasonics for nanoemulsion preparation. Innov. Food Sci Emerg Technol 9:170-175

Landfester K, Willert M, Antonietti M (2000) Preparation of polymer particles in nonaqueous direct and inverse miniemulsions. Macromolecules 33(7):2370-2376

Lif A, Stark M, Nyden M, Holmberg K (2010) Fuel emulsions and microemulsions based on Fischer-Tropsch diesel. Colloids Surf A 354:91-98

Lin CY, Wang KH (2004) Effect of a combustion improver on diesel engine performance and emission characteristics when using threephase emulsions as alternative fuel. Energy Fuel 18(2):477-484

Mata JP, Aswal VK, Hassan PA, Bahadur PJ (2006) A phenolinduced structural transition in aqueous cetyltrimethylammonium bromide solution. Colloid Interface Sci 299:910-915

Overbeek JT (1978) Microemulsions, a field at the border between lyophobic and lyophilic colloids. Faraday Disc Chem Soc 65:7

Porrasa M, Solans C, Gonzalez C, Martinez A, Guinart A, Gutierrez JM (2004) Studies of formation of W/O nano-emulsions. Colloids Surf A 249:115-118

Rosen MJ (1978) Surfactant and interfacial phenomena. Wiley, New York

Ruckenstein E, Chi JC (1960) Stability of microemulsions. J Chem Soc Faraday Trans 71:2

Sadhik BJ, Anand RB (2011) An experimental study in a CI engine using nanoadditive blended water-diesel emulsion fuel. Int $\mathrm{J}$ Green Energy 8:332-348

Shinoda K, Saito H (1968) Solvent properties of surfactant solutions. J Colloid Interface Sci 26:70

Tyagi H, Phelan PE, Prasher R, Peck R, Lee T, Pacheco JR, Arentzen $P$ (2008) Nano Lett 8(5):1410-1416

Wu HL, Ramachandran C, Weiner ND, Rossler BJ (2001) Topical transport of hydrophilic compounds using water-in-oil nanoemulsions. Int J Pharm 220:63

Yang WM, et al. (2013) Impact of emulsion fuel with nano-organic additives on the performance of diesel engine. Appl Energy. doi:10.1016/j.apenergy 